\title{
Bitümlü Sıcak Karışımların Laboratuvar Ortamında Yaşlandırma Yöntemlerinin Karşılaştırılması
}

\author{
Çağla DURMAZ ${ }^{*}$, Burak ŞENGÖZ² Derya KAYA ÖZDEMIIR ${ }^{3}$, Ali TOPAL ${ }^{4}$, Ali ALMUSAWI $^{5}$ \\ 1,5 Dokuz Eylül Üniversitesi, Fen Bilimleri Enstitüsü, İzmir, Türkiye \\ ${ }^{2,3,4}$ Dokuz Eylül Üniversitesi, İnşaat Mühendisliği Bölümü, İzmir, Türkiye \\ *11 cagladurmaz@ gmail.com, ${ }^{2}$ burak.sengoz@deu.edu.tr, ${ }^{3}$ d.kaya@ deu.edu.tr, ${ }^{4}$ ali.topal@ deu.edu.tr, \\ ${ }^{5}$ alialmusawi.engin89@gmail.com
}

\begin{abstract}
Öz: Trafik hacmindeki ve dingil yüklerindeki artışlar, tasarım ve yapım hataları, tekerlek izi oluşumu, düşük sıcaklık çatlakları ve yorulma çatlakları gibi bozuklukların artmasına sebep olmaktadır. Bitümlü bağlayıcının yaşlanması ile doğrudan ilişkili olan bu deformasyonlar, yollardan beklenen performansı ve yolun öngörülen hizmet ömrünü azaltmaktadır. Yukarıda belirtilen deformasyonlara büyük ölçüde sebep olan yaşlanma, uçucu bileşenlerin kaybı ve oksidasyon nedeniyle asfalt bağlayıcının sertleşmesi olarak tanımlanmaktadır. Bu çalışma, National Cooperative Highway Research Program tarafindan önerilen yeni laboratuvar ortamında yaşlandırma yöntemi (NCHRP 09-54) ile mevcut standardı (AASHTO R30) karşılaştırmayı amaçlamaktadır. Yaşlanma etkisini incelemek üzere yaşlandırılmamış ve laboratuvar ortamında kısa ve uzun dönem yaşlandırılmış asfalt numuneleri üzerinde dolaylı çekme mukavemeti deneyleri gerçekleştirilmiştir. Asfalt numunelerinin yaşlanma seviyeleri daha sonra yaşlanma indeksleri kullanılarak değerlendirilmiştir.
\end{abstract}

Anahtar kelimeler: Asfalt, oksidasyon, kısa dönem yaşlanma, uzun dönem yaşlanma, dolaylı çekme mukavemeti.

\section{Comparison of Laboratory Aging Methods of Asphalt-Aggregate Mixtures}

\begin{abstract}
The raise in axle loads, heavy traffic, design and construction errors in the last two decade increase the failures such as rutting, fatigue and low temperature cracking. These deformations decrease the level of performance and service life of the roads. Aging phenomenon, which is defined as the hardening of asphalt binder due to loss of volatile components and oxidation, is the primary factor of the above-mentioned failures. This study aims to evaluate the current standard (AASHTO R30) regarding to the laboratory aging procedure with the new method proposed by National Cooperative Highway Research Program (NCHRP 09-54). In order to investigate the aging effects, the indirect tensile strength tests have been performed on unaged, short and long term laboratory aged asphalt concrete specimens. The aging level of the asphalt concrete specimens had been evaluated through aging indices.
\end{abstract}

Key words: Asphalt, oxidation, short term aging, long term aging, indirect tensile strength.

\section{Giriş}

Sıcaklığa ve çevre koşulları etkisine maruz kalan bitümlü bağlayıcının zamanla sertleştiği bilinmektedir. Zamanla gerçekleşen bağlayıcının sertleşmesi olayına, gevrekleşme veya daha basit bir şekilde yaşlanma adı verilir. Yaşlanma, bitümlü malzemenin viskozitesinin artmasına ve daha kırlgan bir duruma gelmesine sebep olmakta, aynı zamanda, asfalt yüzeyinde çatlaklara ve suya bağlı bozulmalara karşı daha duyarlı olmasına da neden olmaktadır. Yaşlanmanın, kısa dönem yaşlanma ve uzun dönem yaşlanma olarak iki aşamada oluștuğu bilinmektedir [1]. Kısa dönem yaşlanma, karışımın depolanması, plente taşınması, plentte karıştırılması, şantiyeye taşınması, serilmesi ve sıkıştııılması işlemleri sırasında meydana gelmektedir. Bu yaşlanmanın buharlaşmadan kaynaklandığı düşünülmektedir. Uzun dönem yaşlanma, yolun servis ömrü boyunca gerçekleşmektedir. Bu yaşlanmanın ise büyük ölçüde oksidasyondan kaynaklandığı düşünülmektedir [1]. 1850'lerden beri Avrupa'da kaplama malzemesi olarak kullanılan asfaltın sertleşmesi ilk olarak 1900'lerde ABD'de araştırılmaya başlanmıştır [2]. A.W. Dow, 1903'te bitümlü bağlayıcı yaşlanması üzerine ilk belgelenmiş deneyleri gerçekleştirmiş, bitümün sertleşmesini ve özelliklerini kaybetmesini etkileyen faktörleri incelemiştir. [3]. Dow tarafindan gerçekleştirilen çalışmada, sıcak karışım asfalttan geri kazanılan bitümün ağırlık ve penetrasyon özellikleri araştırılmıștır. 1961'de Traxler [4] önem sırasına göre bitümün yaşlanmasını etkileyen faktörleri aşağıdaki gibi listelemiştir:

\footnotetext{
* Sorumlu yazar: durmaz.cagla @ ogr.deu.edu.tr. Yazarların ORCID Numarası: ${ }^{1}$ 0000-0001-5483-0606, ${ }^{2}$ 0000-0003-0684-4880, ${ }^{3}$ 0000-0003$1517-9405,{ }^{4} 0000-0002-2601-1926,{ }^{5} 0000-0002-4507-2492$
} 
1-Oksidasyon,

2-Buharlaşma veya uçucu madde kaybı,

3-Polimerizasyon (aktif ışığa bağlı),

4-Yoğunlaşma polimerizasyonu (1siya bağli).

Traxler (1963), yaptığı başka bir çalışmada bu faktörlerin sayısını 15'e çıkarmıştır [5]. Bu 15 faktörden 4'ünün sertleşmeye en çok sebep olduğu düşünülmüştür. Petersen (1984), karışımların yaşlanmasına ilişkin faktörleri: buharlaşma sonucu bitüm içindeki uçucu bileşenlerin kaybı; oksidasyon reaksiyonundan kaynaklanan bitümün kimyasal bileşimindeki değişiklikler ve moleküler yapıya bağlı olarak tiksotropik etkiler olmak üzere üç ana faktöre indirgemiştir [6]. Daha sonra araştırmacıların çoğu bu üç faktöre dayanan çalışmalar yürütmüşlerdir.

Asfalt karışımlarının laboratuvarda yaşlandırma prosedürlerini geliştirmek için çeşitli araştırmalar yapılmıştır. AASHTO R30 (2002), (Standard Practice for Mixture Conditioning of Hot Mix Asphalt (HMA)), American Association of State Highway and Transportation Officials (AASHTO) tarafindan laboratuvarda asfalt karışımlarının kısa ve uzun süreli yaşlandırılmasını temsil etmek için önerilen mevcut standarttır. Bu standarda göre, kısa dönem yaşlanma etkilerini temsil etmek için gevşek (sıkıştırılmamış) karışım numuneleri, hava sirkülasyonlu etüv içerisinde 135 C'de 4 saat yaşlandırılmalı, uzun dönem yaşlanma simülasyonu için ise numuneler sıkıștırıldıktan sonra hava sirkülasyonlu etüvde 85 C'de 120 saat yaşlandırılmalıdır [7]. Bonaquist (2011) tarafindan, National Cooperative Highway Research Program (NCHRP) 09-43 projesi kapsaminda deneysel çalışmalar yapılmıştır. Yapılan çalışmada, kısa dönem yaşlanmayı laboratuvar koşullarında temsil etmek için, sıkıştırma sıcaklığındaki (Tc) koşullandırma süresi 2 saat olarak belirlenmiş; servis ömrü boyunca yaşlanma için ise temsili olarak daha yüksek bir sıcaklık ve daha uzun yaşlandırma süresi uygun bulunmuştur [8]. Martin ve diğ. (2014) laboratuvar koşullandırma deneylerini içeren NCHRP 09-49 projesini gerçekleştirmişlerdir. Arazide Tc'nin belirlenmesinin zorluğu göz önüne alınarak, sıkıştırma sıcaklığında (Tc) 2 saat koşullandırma yerine standart laboratuvar yaşlandırma protokolü olarak 135 C'de 2 saat koşullandırmayı önermişlerdir [9]. Daha yakın zamanda tamamlanan NCHRP 09-52 projesi, NCHRP 09-43 ve NCHRP 09-49 projelerini harmanlayarak daha kapsamlı bir inceleme sağlamıştır. NCHRP 09-52 projesinde bulgular, AASHTO tarafından önerilen mevcut standardın (AASHTO R30) uzun süreli yaşlandırma prosedürünün uygun bulunduğunu ancak kısa dönem yaşlandırma protokolü olarak mevcut standartta önerilen 4 saat yerine 2 saat boyunca 135 C'de yaşlandırmanın önerildiğini göstermektedir [10]. Kim ve diğ. (2018) tarafindan tamamlanan NCHRP 09-54 projesinde ise uzun dönem yaşlanmayı temsil etmek için yeni bir prosedür geliştirilmiş ve sonuçlar ABD ve Kanada'da bulunan çok çeşitli iklimleri temsil eden dokuz arazi projesinden elde edilen arazi karışımları ile kalibre edilmiş ve doğrulanmıştır. Bu projede, gevşek karışımın yaşlanma protokolü olarak etüv içerisinde 95 C'de koşullandırılma önerilmiştir. Yaşlandırma süreleri ise iklim, yıl ve derinliğe göre belirlenmiştir. Önerilen prosedürde, süreyi belirlemek için kaplama tabakasının $6 \mathrm{~mm}, 20 \mathrm{~mm}$ ve $50 \mathrm{~mm}$ derinliklerinde 4,8 ve 16 yıllık arazi yaşlanması için laboratuvar yaşlandırma süresi haritaları oluşturulmuştur. ABD'de yapılan çalışmada, 4 yıllık servis ömrüne sahip bir yol için önerilen yaşlandırma süresi 3 ila 5 gün olarak belirlenmiştir. Genelde hesaplamalar için 4 yıllık bir süre ve $20 \mathrm{~mm}$ derinlik dikkate alınmaktadır [11].

$\mathrm{Bu}$ çalışmanın amacı, asfalt karışımlarının kısa ve uzun dönem yaşlandırılmasında National Cooperative Highway Research Program tarafından önerilen yaşlandırma yöntemi NCHRP 09-54 ile mevcut yaşlandırma standardını (AASHTO R 30) karşılaştırmaktır.

\section{Materyal ve Yöntem}

Deneysel çalışmalarda, bitümlü bağlayıcı olarak Türkiye Petrol Rafineleri A.Ş.’ne bağlı İzmir Aliağa Rafinerisinden temin edilen 50/70 penetrasyon sınıfı bağlayıcı kullanılmıştır. Geleneksel saf bitümlü bağlayıcı özelliklerini tespit etmek için penetrasyon, yumuşama noktası, düktilite, viskozite, parlama, ince film halinde 1sıtma, ince film halinde 1sıtma deneyi sonrası penetrasyon ile ince film halinde 1sıtma deneyi sonrası yumuşama noktası deneyleri uygulanmıştır. Geleneksel bitümlü bağlayıcı deney sonuçları Tablo 1'de sunulmuştur.

Sıcak asfalt karışımlarında agrega olarak Dere Grup A.Ş. İzmir Belkahve taş ocağından temin edilen kalker kullanılmıştır. Agrega özelliklerini belirlemek amacıyla özgül ağırlık, Los Angeles aşınma, sodyum sülfat sağlamlık, ince agrega köşelilik ve yassılık indeksi deneyleri uygulanmıştır. Agrega deney sonuçları Tablo 2'de verilmiştir. Karışım agrega gradasyonu, Karayolları Teknik Şartnamesi’nde aşınma tabakaları için belirtilen Tip 1 gradasyon limitlerine uygun olarak seçilen gradasyon değerleri Tablo 3 'te verilmiştir 
Tablo 1. Saf bitüme uygulanan klasik bitüm deneyleri sonuçları.

\begin{tabular}{|c|c|c|c|}
\hline Test & Standartlar & Sonuçlar & Limitler \\
\hline Penetrasyon (25 C; $0.1 \mathrm{~mm}$ ) & ASTM D5 & 65 & $50-70$ \\
\hline Yumuşama Noktası ( C) & ASTM D36 & 51 & $46-54$ \\
\hline Viskozite (135 C)-Pa.s & ASTM D4402 & 0,412 & - \\
\hline Viskozite (165 C)-Pa.s & ASTM D4402 & 0,104 & \\
\hline Düktilite $(25 \mathrm{C} ; \mathrm{cm})$ & ASTM D113 & 100 & - \\
\hline Özgül Ağırlık & ASTM D70 & 1,030 & - \\
\hline Parlama Noktas $1\left({ }^{\circ} \mathrm{C}\right)$ & ASTM D92 & +260 & $230(\min )$ \\
\hline Penetrasyon İndeksi (PI) & - & 0,35 & - \\
\hline RTFOT & ASTM D2872-12 & & \\
\hline Kütle değişimi (\%) & - & 0,160 & $0.5(\max )$ \\
\hline RTFOT sonrası penetrasyon & ASTM D5 & 53 & $50(\min )$ \\
\hline $\begin{array}{l}\text { RTFOT sonras } 1 \text { kalicı } \\
\text { penetrasyon }(\%)\end{array}$ & ASTM D36 & 82 & $50(\min )$ \\
\hline $\begin{array}{c}\text { RTFOT sonrası yumuşama } \\
\text { noktası }\left({ }^{\circ} \mathrm{C}\right)\end{array}$ & ASTM D36 & 58 & $48(\min )$ \\
\hline
\end{tabular}

Tablo 2. Kalker agregasının fiziksel özellikleri.

\begin{tabular}{|c|c|c|c|}
\hline Test & Standatlar & Sonuçlar & Limitler \\
\hline Hacim Özgül Ağırlık (Kaba agrega) & ASTM C127 & 2,704 & \\
\hline Hacim Özgül Ağırlı (İnce Agg.) & ASTM C128 & 2,691 & - \\
\hline Özgül Ağırlık (Filler) & & 2,732 & max. 45 \\
\hline Los Angeles Aşınma (\%) & ASTM C 131 & 22,6 & max. 10 \\
\hline Yassılık İndeksi (\%) & ASTM D 4791 & 7,5 & $\operatorname{max.~} 10-20$ \\
\hline Sodyum Sülfat Sağlamlık (\%) & ASTM C 88 & 1,47 & $\min .40$ \\
\hline İnce Agrega Köşeliliği & ASTM C 1252 & 47,85 & \\
\hline
\end{tabular}

Tablo 3. Kalker agregası için seçilen gradasyon.

\begin{tabular}{|c|c|c|}
\hline Elek No. & Gradasyon $(\%)$ & Şartname Limitleri \\
\hline $19 \mathrm{~mm}$ & 100 & 100 \\
\hline $12.5 \mathrm{~mm}$ & 92 & $88-100$ \\
\hline $9.5 \mathrm{~mm}$ & 73 & $72-90$ \\
\hline No.4 & 44,2 & $42-52$ \\
\hline No.10 & 31 & $25-35$ \\
\hline No.40 & 12 & $10-20$ \\
\hline No.80 & 8 & $7-14$ \\
\hline No.200 & 5,3 & $3-8$ \\
\hline
\end{tabular}




\subsection{Marshall tasarım yöntemi}

Optimum bitüm içeriğini bulmak için Marshall tasarım yöntemi kullanılmıştır. Her bir bitüm yüzdesi için üç deney numunesi hazırlanmıştır. Tüm deney ve ölçüm sonuçlarına göre bitüm yüzdesi-Stabilite, Akma, Boşluk, mineral agregalar arasındaki boşluk (VMA) ve asfaltla dolu boşluk (VFA) grafikleri çizilmiştir. Sonuç olarak, aşınma tabakası için standartta belirtilen \%3 ile \%5 hava boşluğu ortalamasına (\%4) karşılık gelen bitüm miktarı optimum bitüm içeriği olarak belirlenmiştir.

\subsection{Yaşlandırma yöntemleri}

Laboratuvarda sıcak asfalt karışımlarının yaşlanmasını temsil etmek için numuneler; yaşlandırılmamış numuneler; kısa dönem yaşlandırılmış numuneler ve uzun dönem yaşlandırılmış numuneler olmak üzere üç farklı gruba ayrılmıştır. Kısa ve uzun dönem yaşlandırma koşulları ve kullanılan yöntemlerin adları Tablo 4'te sunulmaktadır. Uzun dönem yaşlandırma yöntemi uygulanmadan önce numunelerin kısa dönem yaşlandırılması gerekmektedir.

Tablo 4. Laboratuvar Ortamında Yaşlandırma Yöntemleri.

\begin{tabular}{|c|c|c|c|c|c|c|}
\hline \multirow{2}{*}{ Yöntem } & \multicolumn{4}{|c|}{ Yaşlandırma Koşulları } \\
\cline { 2 - 7 } & \multicolumn{2}{|c|}{ Kısa Dönem Yaşlandırma } & \multicolumn{3}{c|}{ Uzun Dönem Yaşlandırma } \\
\cline { 2 - 7 } & $\begin{array}{c}\text { Sicaklık } \\
(\text { C) }\end{array}$ & $\begin{array}{c}\text { Süre } \\
\text { (saat) }\end{array}$ & $\begin{array}{c}\text { Karışım } \\
\text { Durumu }\end{array}$ & $\begin{array}{c}\text { Sicaklık } \\
(\text { C) }\end{array}$ & $\begin{array}{c}\text { Süre } \\
\text { (saat) }\end{array}$ & Karışım Durumu \\
\hline AASHTO R30 & \multirow{2}{*}{135} & 4 & Gevşek & 85 & 5 & S1kıştırılmış \\
\cline { 3 - 7 } & NCHRP 09-54 & 4 & Gevşek & 95 & $4 *$ & Gevşek \\
\hline
\end{tabular}

* hesaplamalar ile belirlenen değer

Daha önce belirtildiği gibi, mevcut standart deney yöntemi (AASHTO R30) gevşek (sıkıştırılmamış) asfalt karışımının 4 saat 135 C'de hava sirkülasyonlu etüvde kısa dönem yaşlandırılmasını; kısa dönem yaşlandırılmış numunelerin daha sonra sıkıştırılarak numunelerin 120 saat boyunca 85 C'de uzun dönem yaşlandırılmasını içermektedir. NCHRP 09-54 yönteminde, AASHTO R30 standart yöntemi ile aynı kısa dönem yaşlandırma koşulu uygulanmaktadır (135 C'de 4 saat). Uzun dönem yaşlandırmada ise mevcut yöntemden farklı olarak sıkıştırılmış asfalt numuneleri yerine gevşek karışım kullanılmış ve yaşlandırma işlemi 95 C'de gerçekleştirilmiştir. Tablo 4'te belirtilen yaşlandırma süresi için aşağıdaki denklem (Denklem 1) kullanılmıştır:

$$
t_{\text {oven }}=\sum_{i=1}^{N} D * A * \exp \left(-\frac{E a}{R * T i}\right) / 24
$$

Burada toven = arazi yaşlanmasını yansıtmak için 95 C'de gerekli etüv yaşlandırma süresi (gün), D = derinlik düzeltme faktörü, $\mathrm{A}=$ frekans faktörü, Ea = aktivasyon enerjisi, $\mathrm{R}=$ evrensel gaz sabiti (bu değer $0.0831 \mathrm{~kJ} / \mathrm{mol} . \mathrm{k}$ olarak alınmıştır.), $\mathrm{Ti}=$ ilgilenilen saatte ilgilenilen derinlikteki kaplama sıcaklığını ( $\mathrm{K}$ ) ifade etmektedir.

$\mathrm{Bu}$ çalışmada, $20 \mathrm{~mm}$ derinlik dikkate alınmış, derinlik düzeltme faktörü (D), frekans faktörü (A) ve aktivasyon enerjisi (Ea) Tablo 5'ten elde edilmiştir. 
Tablo 5. İklimsel yaşlanma indeksi katsayıları [11].

\begin{tabular}{|c|c|c|c|}
\hline Kaplama Tabakası & $\begin{array}{c}\text { Derinlik Düzeltme } \\
\text { Faktörü } \\
(\mathrm{D})\end{array}$ & $\begin{array}{c}\text { Frekans Faktörü } \\
(\mathrm{A})\end{array}$ & $\begin{array}{c}\text { Aktivasyon Enerjisi } \\
\text { (Ea) }\end{array}$ \\
\hline $\begin{array}{c}\text { Aşınma tabakası }(6 \\
\text { mm) }\end{array}$ & 1,0000 & 1,40962 & 13,3121 \\
\hline $20-\mathrm{mm}$ derinlik & 0,4565 & 1,40962 & 13,3121 \\
\hline $\begin{array}{c}\text { Daha derindeki } \\
\text { tabakalar }\end{array}$ & 0,2967 & 1,40962 & 13,3121 \\
\hline
\end{tabular}

Kaplama sıcaklı̆̆ı (Ti), Witczak [12] tarafından geliştirilen aşağıdaki denklem (Denklem 2) ile belirlenmiştir.

$$
T_{i}=T_{a} *\left[1+\frac{1}{z+4}\right]-\frac{34}{z+4}+6
$$

$\mathrm{T}_{\mathrm{i}}=$ saatlik kaplama sıcaklığı $\left({ }^{\circ} \mathrm{F}\right), \mathrm{T}_{\mathrm{a}}=$ saatlik hava sıcaklığı $\left({ }^{\circ} \mathrm{F}\right), \mathrm{z}=$ kaplama yüzeyinin altındaki derinlik (Bu değer $20 \mathrm{~mm}$ derinliğe karşılık gelen 0,79 inç olarak alınmıştır).

$T_{i}$ 'nin hesaplanmasında, meteorolojik parametreleri eksiksiz ve temsil gücü iyi olan İzmir'in 4 ana ilçesi (Dikili, Aliağa, Menemen, Buca) üzerinden istasyon noktaları seçilmiş olup, 2015, 2016, 2017 ve 2018 yılları için saatlik hava sıcaklığı değerleri (Ta) Meteoroloji Genel Müdürlüğü'nden temin edilmiştir. 4 yıllık süre, daha önce belirtildiği gibi NCHRP 09-54 yönteminin tavsiyesine dayanmaktadır. 1 numaralı denklemde tüm değişkenlerin değerleri belirlendikten sonra toven değerleri İzmir'in 4 ana ilçesi bazında hesaplanmıştır (Tablo 6).

Tablo 6. İzmir ili 4 ana ilçe için $t_{\text {oven }}$ değerleri.

\begin{tabular}{|c|c|c|c|c|c|}
\hline İlçe/Yıllar & 2015 (günler) & 2016 (günler) & 2017 (günler) & 2018 (günler) & Toplam (günler) \\
\hline Dikili & 1,035 & 1,043 & 1,037 & 1,057 & 4,17 \\
\hline Aliağa & 1,039 & 1,052 & 1,039 & 1,062 & 4,19 \\
\hline Menemen & 1,039 & 1,052 & 1,039 & 1,063 & 4,19 \\
\hline Buca & 1,038 & 1,052 & 1,040 & 1,061 & 4,19 \\
\hline
\end{tabular}

Tablo 6'da belirtildiği gibi NCHRP 09-54 yöntemi dahilinde laboratuvar ortamında uzun dönem yaşlandırma işlemi için ortalama 4 günlük sürenin kullanılması uygundur.

\subsection{Dolaylı çekme mukavemeti testi}

Laboratuvarda hazırlanan numunelerin kısa ve uzun dönem yaşlanma durumunu değerlendirmek için, basit olması ve numunelerin kolaylıkla üretilebilmesi sebebiyle en çok uygulanan testlerden biri olan çekme mukavemeti (ITS) testi yapılmıştır [13]. Laboratuvarda hazırlanan silindirik asfalt numuneleri yükleme çerçevesine yerleştirildikten sonra yük, düşey düzlemde $(51 \mathrm{~mm} /$ dakika yükleme hızında) uygulanmış ve numunenin yatay yönünde oluşan gerilme yükü ölçülmüsşür. Numunenin dayanabildiği en yüksek yük Marshall cihazı tarafindan otomatik olarak belirlenmiştir. Malzemelerin ITS değerleri aşağıdaki denklem (Denklem 3) kullanılarak elde edilebilir.

$$
S t=\frac{2000 x P}{\pi x t x D}
$$

$\mathrm{S}_{\mathrm{t}}=$ Dolaylı çekme mukavemeti (ITS), $\mathrm{kPa}$.

$\mathrm{P}=$ Uygulanan maksimum yük, $\mathrm{N}$.

$\mathrm{t}=$ =Numunenin kalınlığı, $\mathrm{mm}$. 
$\mathrm{D}=$ Numunenin çapı $1, \mathrm{~mm}$.

Laboratuvarda hazırlanan asfalt karışımlarının yaşlanma etkilerini değerlendirmek için ITS değerlerine ek olarak, yaşlanma indeksleri de araştırılmıştır. Kısa ve uzun dönem yaşlandırılmış numunelerin ITS değerleri ile yaşlandırılmamış numunelerin ITS değerleri arasındaki oran kısa dönem yaşlanma indeksi (SAI) ve uzun dönem yaşlanma indeksi (LAI) olarak hesaplanmıştır.

\section{Deneysel Çalışma Sonuçları}

\subsection{Marshall tasarım yöntemi sonuçları}

Deneysel çalışmaların sonucu olarak, $\% 4$ hava boşluğuna karşılık gelen optimum bitüm içeriği $\% 4,8$ (agrega ağırlığınca) olarak tespit edilmiştir. Tablo 7'de belirtildiği gibi, \%4 hava boşluğu seviyesine karşıllk gelen tüm parametreler şartname sınırları içerisindedir.

Tablo 7. Marshall testi sonuçları.

\begin{tabular}{|c|c|c|}
\hline Parametre & Sonuç & Şartname \\
\hline Optimum Bitüm içeriği (\%) & 4,8 & $4-7$ \\
\hline Stabilite (kg) & 1135 & $900(\mathrm{~min})$ \\
\hline Akma (mm) & 2,60 & $2-4$ \\
\hline Asfaltla dolu boşluk VFA (\%) & 71 & $65-75$ \\
\hline $\begin{array}{c}\text { Mineral agrega içerisindeki } \\
\text { boşluk VMA (\%) }\end{array}$ & 14 & $14-16$ \\
\hline
\end{tabular}

\subsection{Dolaylı çekme mukavemeti testi sonuçları}

Yaşlandırılmamış, kısa dönem yaşlandırılmış ve uzun dönem yaşlandırılımıs numunelerin ITS değerleri Şekil 1'de sunulmuştur. Sonuç olarak, her iki yöntemde de uzun dönem yaşlandırılmış numunelerin ITS değerleri kısa dönem yaşlandırılmış ve yaşlandırılmamış numunelerin ITS değerlerinden daha yüksektir. Dolaylı çekme gerilmesi değerlerindeki artış, yaşlanmanın etkisinin bir göstergesi olarak kabul edilebilir. Her iki yöntemin de kısa dönem yaşlandırma koşulları aynı olduğu için, beklenildiği gibi ITS değerleri de aynıdır. Ancak uzun dönem yaşlandırılmış numunelerin ITS değerleri incelendiğinde NCHRP 09-54 yönteminin daha yüksek ITS değerlerine sebep olduğu söylenebilir.

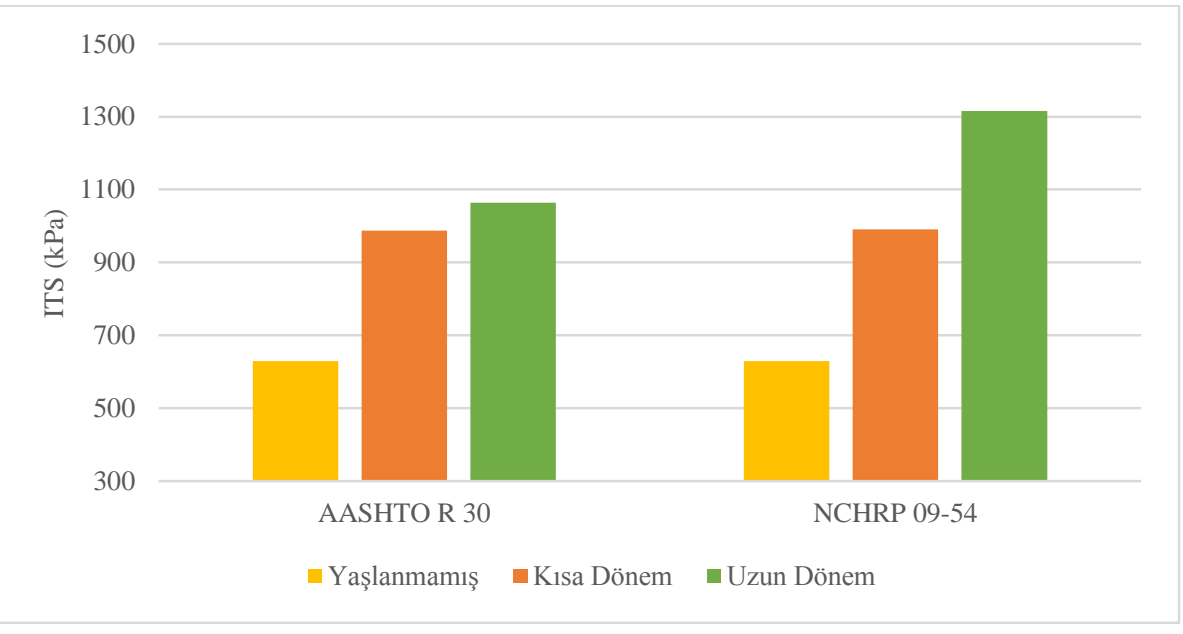

Şekil 1. Dolaylı çekme deneyi sonuçları. 
Kısa dönem yaşlandırılmış ve uzun dönem yaşlandırılmış numunelerin ITS değerleri ile yaşlandırılmamış numunelerin ITS değerleri arasındaki oran kısa dönem yaşlanma indeksi (SAI) ve uzun dönem yaşlanma indeksi (LAI) olarak hesaplanmış ve Şekil 2'de sunulmuştur.

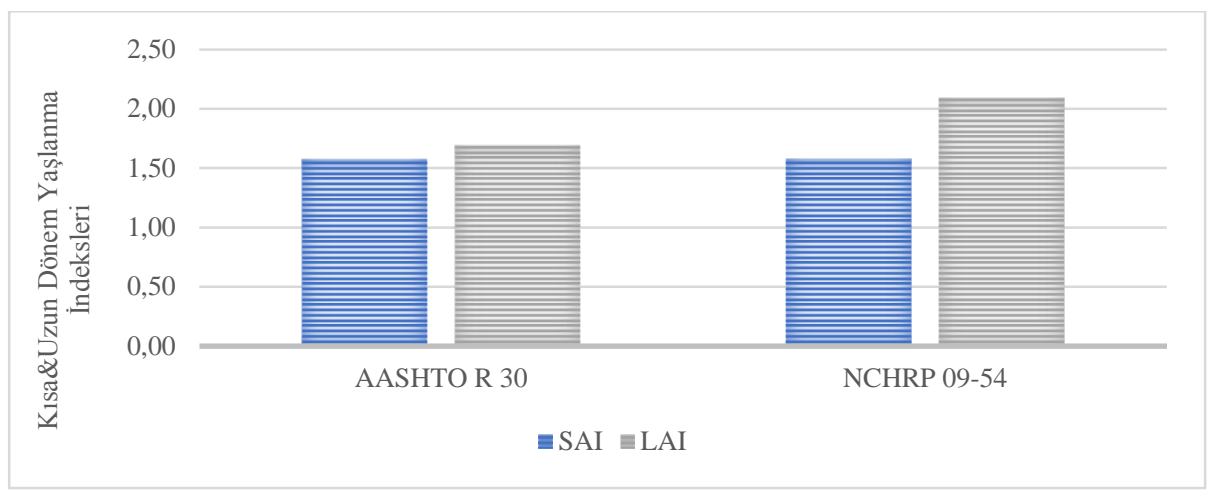

Şekil 2. Yaşlanma indeksi sonuçları.

Yaşlanma indeksi değerlerine bakıldığında, değer ne kadar düşük olursa, bitümlü karıșımın yaşlanma etkisine o kadar az maruz kaldığı söylenebilir. AASHTO R30 ve NCHRP 09-54 yöntemleri, kısa dönem yaşlandırma koşulları aynı olduğu için beklenildiği gibi benzer kısa dönem yaşlanma indeksi değerleri göstermiştir. Uzun dönem yaşlanma indekslerine bakıldığında ise, NCHRP 09-54 yöntemi ile yaşlandırılmıș numunelerin, AASHTO R30 yönteminden daha yüksek bir sıcaklıkta ve daha kısa bir sürede koşullandırılmaları sebebiyle belirgin seviyede daha yüksek yaşlanma indeksi değerine sahip oldukları gözlenmiştir. Bu artıştan yola çıkılarak NCHRP 09-54 yönteminde yaşlanma etkisinin daha fazla olduğu söylenebilir.

\section{Sonuçlar ve Değerlendirme}

Bu çalışmada, mevcut standart (AASHTO R30) ve NCHRP 09-54 laboratuvar yaşlandırma yöntemleri dolaylı çekme mukavemeti ve yaşlanma indeksi parametreleri göz önünde bulundurularak karşılaştırılmıştır. Elde edilen sonuçlar ve değerlendirmeler aşağıda sunulmuştur:

$\checkmark$ İncelenen yaşlandırma yöntemleri için, numunelerin dolaylı çekme mukavemeti (ITS) değerleri, yaşlandırma süreleri arttıkça yükselmektedir. ITS'deki artış asfaltın, daha sert, kırılgan ve yorulma çatlaklarına daha duyarlı hale geldiğinin bir göstergesidir. Dolayısı ile ITS değerinin yüksek olması istenmeyen bir durumdur. Ayrıca, daha yüksek ITS'e sahip numunelerin yorulma ömrü belirli bir gerilme seviyesinde azalmaktadır. Yaşlanma, sertliği arttırarak asfalt malzemelerinin çatlaklara karşı duyarlılığını arttırdığından, yaşlandırılmış karışımlarda çatlak oluşumu gözlenme olasılığının, yaşlandırılmamış karışımlardan daha yüksek olması beklenmektedir.

$\checkmark$ Hava sirkülasyonlu etüvde kısa dönem yaşlandırılmış numuneler arasında, her iki yönteme ilişkin kısa dönem yaşlandırma koşullarının önemli bir farklılık göstermemesi nedeniyle, araştırılan yöntemlerin her ikisi de benzer ITS değerleri vermiştir. Numunelerin yaşlanma özelliklerinin daha iyi değerlendirilebilmesi için hesaplanan kısa ve uzun dönem yaşlanma indekslerinden elde edilen bulgular 1şı̆̆ında, daha düşük yaşlanma indeksi değerlerine sahip karışımlarda yaşlanmanın daha az etkisi olduğunu düşünmek mümkündür.

$\checkmark$ NCHRP 09-54 yönteminde ise ilgili meteorolojik parametreler toplanarak hesaplamalar yapılmıştır. Yapılan hesaplamalar sonucunda İzmir bölgesi için uzun dönem yaşlandırma süresi 4 gün olarak belirlenmiştir. Bu nedenle, uzun dönem yaşlandırma koşulu olarak gevşek numunelerin 4 gün 95 C'de yaşlandırılması, sıkıştırılmış numunelerin 85 C'de 120 saat (5 gün) yaşlandırılmasına alternatif olarak önerilebilir. Hangi yöntemin daha efektif sonuçlar verdiğini görebilmek adına aynı gradasyona sahip araziden alınan belirli bir hizmet ömrüne sahip (yaşlanmış) numuneler ile laboratuvar ortamında yaşlandırılan numunelerin ITS değerlerinin belirlenip karşılaştırılması önerilmektedir. 


\section{Teșekkür}

Yazar, bu çalışmanın gerçekleşmesine katkısından dolayı Dokuz Eylül Üniversitesi Fen Bilimleri Enstitüsü’ne teşekkür etmektedir.

\section{Kaynaklar}

[1] Bell CA, Wieder AJ, Fellin MJ. Laboratory ageing of asphalt-aggregate mixtures: field validation. Washington DC: Strategic Highway Research Program, 1994.

[2] Croney D. The Design and Performance of Road Pavements. London, England: Her Majesty's Stationery Office, 1977.

[3] Dow AW. Asphalt experiments at Washington. Engineering News Record (ENR) 1903; 47(18): 18-25.

[4] Traxler RN. Relation between Asphalt Composition and Hardening by Volatilization and Oxidation. American Association of Asphalt Paving Technologist (AAPT) 1961; 30: 359-377.

[5] Traxler RN. Durability of Asphalt Cements. Association of Asphalt Paving Technologists (AAPT) 1963; 32: 44-58.

[6] Petersen JC. Chemical Composition of Asphalt as Related to Asphalt Durability: State of the Art. Transportation Research Record (TRR) 1984; 999: 13-30.

[7] AASHTO R 30-02. "Standard Practice for Mixture Conditioning of Hot-Mix Asphalt (HMA)", American Association of State Highway and Transportation Officials (AASHTO), Washington DC, 2002.

[8] Bonaquist RF. Mix design practices for warm mix asphalt. Transportation Research Board (TRB) 2011; 691.

[9] Martin AE. Evaluation of the moisture susceptibility of WMA technologies. Transportation Research Board (TRB) 2014; 763.

[10] Yin F, Martin AE, Arámbula-Mercado EDITH, Newcomb D. Short-Term Laboratory Conditioning of Asphalt Mixtures. Relationships of Laboratory Mixture Aging to Asphalt Mixture Performance Transportation Research Board (TRB) 2018; 21.

[11] Kim YR, Castorena C, Elwardany MD, Rad FY, Underwood S, Gundla A, Gudipudi P, Farrar MJ ve diğerleri. Longterm aging of asphalt mixtures for performance testing and prediction. Transportation Research Board (TRB) 2018.

[12] Witczak MW. Design of full-depth asphalt airfield pavements. Third International Conference on the Structural Design of Asphalt Pavements; 11-15 September 1972; London, England.

[13] Yılmaz M, Kök BV, Yalçın E. Farklı Katkılar İçeren Bitümlü Sıcak Karışımların Yorulma Ömürlerinin İncelenmesi. Fırat Üniversitesi Mühendislik Bilimleri Dergisi 2017; 29(2): 173-183. 